\title{
A case study on the food safety issues of college students in
} Taiwan

Dong, Thi Tra My

Department of Business Administration, Lunghwa University of Science and Technology, Taiwan (annie.ju.1990@gmail.com)

Ching, Gregory S.

Graduate Institute of Educational Leadership and Development, Fu Jen Catholic University, Taiwan (gregory_ching@yahoo.com; 094478@mail.fju.edu.tw)

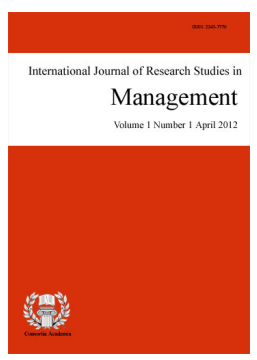

ISSN: $2243-7770$ Online ISSN: 2243-7789

OPEN ACCESS

Received: 6 November 2014

\section{Abstract}

The research is designed as a case study of students in Taiwan. It uses the quantitative method by questionnaire distribution. There are 369 participants in this study. The findings denote knowledge has positive impact students' on both their attitude and behavior. Furthermore, the result shows the need to enhance knowledge of students as well as their confidence in food safety issue. Thenceforth, this brings out some practical contribution for the academia, food industry and government. Besides, the improved model is suggested in theoretical contribution.

Keywords: food safety; Taiwan; college student; the KAP survey model; quantitative study 


\section{A case study on the food safety issues of college students in Taiwan}

\section{Introduction}

As a basic physiological necessity of human being, eating keeps people survive. Therefore, food is an essential contributor to physical well-being, a main source of pleasure, worry and stress (Rozin, Fischler, Imada, Sarubin, \& Wrzesniewski, 1999). Additionally, a famous saying suggests that "we are what we eat", however, it is not easy to answer "what to eat" in current circumstances, when a number of food scandals are alarmed recently. Indeed, within the last two decades, there were widespread food scandals (e.g. BSE crisis, dioxin crisis, melamine case, etc.), global fears of foods (food additives, residues, new technologies, mass production of food industry, etc.) along foodborne outbreaks which highlights consumers' concerns and authorities attention to food safety (Banati, 2011).

Food safety refers to the potential hazards related to food that can lead to human illness. Food safety issue is presently a global health-related concern in community. Besides, foodborne illness epidemic is a critical public health problem which is interrelated to the food safety management in a particular country. Moreover, this outbreak has become a burden on millions of people worldwide annually, or about one-third of the global population (WHO, 2004). Food contamination generates an enormous social and economic encumbrance on communities and their health systems (Jevsnik, Hlebec, \& Raspor, 2007). Hence, food related infection becomes a common health concern in many countries. Additionally, Redmond and Griffith (2003) discussed that the developing countries and the developed nations all suffer foodborne disease and the incidence associated those infections is growing.

In Taiwan, Food and Drug Administration (FDA) of Health department collected the data of foodborne disease records during 20 years, from 1991 to 2010 (Cheng, Kuo, Chi, Lin, Lee, Feng, \& Tsai, 2013). Whereby, 4284 foodborne disease incidence were recorded domestically including 82,342 victims within that period. More notably, Cheng et al. (2013) also compared the 20 years period, then concluding that the average annual number of foodborne illness outbreaks during 2001-2010 is considerably higher than during 1991-2000. Furthermore, they reviewed that all contaminated products related to the illegal usages of food additive were confiscated from the market by the manufacturers and demolished by the Taiwanese government in June, and importantly, this event is also known as the "2011 Taiwan Food Scandal" (Yen, Lin-Tan, \& Lin, 2011). Most recently, "2013 Taiwan Food Scandal" broke out, as the second major food scare in two years, denoting the ongoing food safety incidents in this country that associates cooking oil, milk, rice, alcoholic beverages and health pills.

In common with the rapid growth rate of economy, the substantial rise of individual and household income has been granting consumers more purchasing power. Unlike the past time back to 1990s when eating was mostly perceived as a necessary task for survive; consumers have increasingly inclined to enjoy savory food. However, it does not seem enough with eating in right time and eating delicious food, but it is also about eat healthy and hygienic food. In fact, the demand for fresh, clean and hygienic food has been grabbing paramount of consumer's attention since there has been number of records about food poison and foodborne illness up to now. As consistent to that common tendency, the necessity for hygienic food is becoming a prerequisite concern when it is coming to food consumption.

Unfortunately, in pursuit of profit as merely profit-focused seekers, some food manufacturers have shown signs of unethical business, increasing the amount of preservatives to prolong the expiration duration of food or involving the use of forbidden poisonous chemical in the making of products in defiance of consumers' health. The lax management in term of food safety from competent authorities also appears alongside to make the law infringement of these enterprises worse. Appealing package with nutrition facts beneficial to consumers, in conjunction with the blossoming of media also exposes its negative effect since many commercial shot about 
food products release false information about products, its making, and ingredients that lead consumers to misperception. It is often not long after launching to the market with the backup of well-scripted advertisement both online and offline, people can find out true facts about food products that they commonly consume on daily basis. Many cases are explicitly conflicting between false advertisement and true facts, resulting to the confusion thus making it hard for consumers to select right food for consumption.

In front of these highly varying happenings, consequently, consumers become more interested in and worried about food safety issues. Moreover, majority individuals of all ages generally think that they know the appropriate solution for food safety issue, their self-reported food-handling behaviors in the previous researches notwithstanding did not confirm such confidence (Unusan, 2007). The most valuable asset of people is health, college students will become the powerful consumer force in the future, and hence their health need to be taken care of thoroughly. College students would certainly be a backbone of any country. More importantly, it is their future roles for a next healthy generation. With all above respects, the motivation is defined to conduct this research targeting college students as research population, in the context of food safety issue in Taiwan.

\section{Model application and objectives}

This study uses KAP survey model to identify the level of students' knowledge, attitude and practice as well as the correlations among three dimensions each other. A major research on food safety issue of food handlers and students using KAP model surveys has been done globally. Nevertheless, there is no study which discovered knowledge, attitude and practice of college students towards food safety in Taiwan. It has become urgent in the current situation since Taiwan suffered 2 severe Food scandals in 2011 and 2013 that detrimentally hurtled the core perception of Taiwan food industry, claimed Taipei Times. Taiwanese consumers have responded in worries and confusion, and accordingly discredit the food suppliers. Therefore, the comprehensive understanding about knowledge, attitude and behavior of consumers become more important than ever that enable competent authorities to initiate proper remedy to control food safety, thus help recover the consumers' trust. Additionally, educational campaigns or activities related to food, where college students are a major target, become a must.

Besides, the relationship of three pillar dimensions in this model still remains some arguments. Therefore, through model development of current study, this study aims to discover correlations of knowledge, attitude and practices as three hypotheses. In short, the research questions of this researching are as follows:

To what level are the knowledge, attitude, and practice towards food safety issues among Taiwanese college students?

$>\quad$ How are the Knowledge, Attitude and Practice correlated?

$>\quad$ How should the competent authorities (such as Government, Food industry, the media, etc.) act to ensure food safety issue for consumers?

More precisely, the study aims to investigate students' knowledge, attitude, and practice extent towards food safety issue, such as:

$>$ Consumers' general knowledge about food safety issue.

$>\quad$ Trustworthy sources perceived by consumers where they can obtain food safety information in their awareness

$>$ Organization perceived to hold responsibilities in food safety in their awareness

$>$ Consumers' attitudes towards organic food

$>\quad$ Consumers' attitudes towards willingness-to-pay 
$>$ Consumers' confidence in food safety context

$>\quad$ The eating frequency of consumers in various dining-venues during last month

$>$ Factors consumers look at when selecting dining-units

$>$ Label information consumers read when deciding to purchase or consume food

\subsection{Implications of the study}

The observation on knowledge, attitude and behavior of students in relation to food safety obtained from this study brings out some suggestions to the academia, food industry and government. Thenceforth, the students' knowledge and trust towards food safety can be improved through education and other particular activities. In addition, this study exposes the critical role of Government in the general management on such issue. Inferred from practical perspective, it is arguable to recognize the contribution of laws and legislation in keeping Food safety on right track. Therefore, the addition of element Policy should be made highly applicable to enhance the competence of original KAP model in food safety management.

\subsection{The model}

This study establishes three hypotheses in context of food safety issue, as follows:

Hypothesis 1: Knowledge has positive impact on Attitude (H1)

$>\quad$ Hypothesis 2: Knowledge has positive impact on Practice (H2)

Dypothesis 3: Attitude has positive impact on Practice (H3)

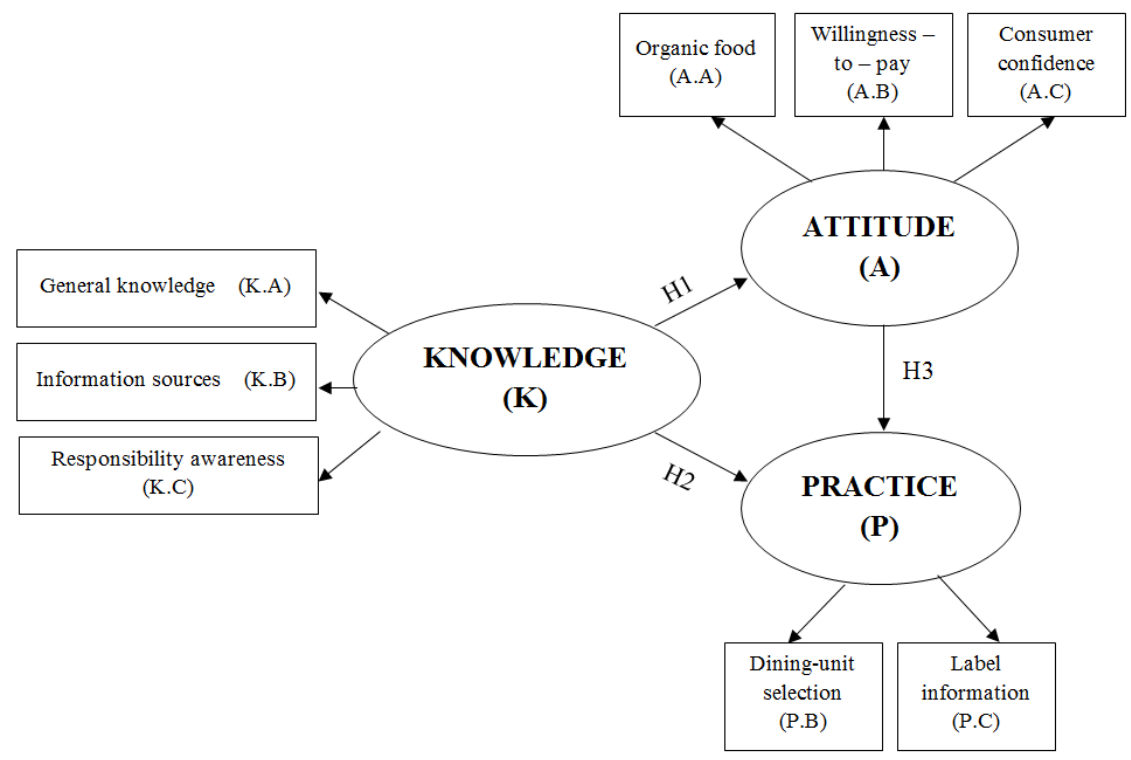

Figure 1. The model

\section{Methodology}

\subsection{Research design}

This paper is a case study of Taiwanese students in Lunghwa University of Science and Technology in 
A case study on the food safety issues of college students in Taiwan

Taiwan. A case study is an in-depth study of a particular research problem rather than an all-encompassing statistical survey. It frequently uses to narrow down a very broad field of research into one or a few easily researchable examples. Moreover, the case study research design is also useful for examining whether a particular model actually applies to circumstances in the real world. Therefore, it is a useful design, especially in the cases there is not much comprehend about a phenomenon.

\subsection{Research tool}

The KAP model survey is conducted in current study as a quantitative method. The goal of quantitative methods of data collection is to quantify and measure a phenomenon through the use of questionnaires and statistical processing of the information collected (Sybille G. et al., 2011). Part 1 is used to collect data on demographic, including respondents' age, gender, year level, the amount of money spending in food consumption monthly. This part also includes a question regarding whether they have got or known about food-borne illness by asking: "Have you ever had food-borne illness or heard about anybody catching it?" If respondents answered "yes", they are asked the follow-up multiple choices question: "Where most likely?", and the answers are offered including: "at home”, "at canteens of schools", "at street food vendors" (in markets/ night markets), "at restaurants" and "at leisure facilities" (e.g., theme parks, cinema, bowling alley, etc.).

Part 2 contains questions relating to Knowledge section. There are three factors in this section: general knowledge, information sources and responsibility awareness which respondents are asked to rate for. Firstly, general knowledge consists 9 questions to test how much participants aware of chemical issues (question numbers: $1,2,3)$, health issues $(4,5)$ microbiological issues $(6,7,8)$ and organic food $(9)$. These questions are revised from section 2 of Customer Attitudes towards issues in food safety's survey (Ms. Brewer \& M. Rojas, 2007), except for question 9. Secondly, the part of information sources follows with six questions to assess the extent of given sources in order to trust food safety information offered. It is referenced from 2013 Food \& health survey of International Food Information Council Foundation. Lastly, the third variable measures responsibility awareness of respondents based on the research of Jevenik, Hlebac and Raspor (2007) to create five questions. The answers are offered using an item scale that called the 5-point Likert- type scale arranged where $1=0 \%, 2=25 \%, 3=50 \%, 4=75 \%$ and $5=100 \%$.

Part 3 focuses on Attitude section. It has three features of attitude towards organic food, willingness-to-pay and consumer confidence. In organic food factor, all respondents are asked five questions for the level of their agreements in a variety of statements about organic food; questions' resource is from Mei-Fang Chen (2007). Next feature, participants are probed their attitudes towards willingness-to-pay with four questions which are drafted by researcher. By creating this factor, the study wants to observe consumers' thoughts about the food considered as high quality (e.g., organic food) as well as whether they have demonstrated a preference for this type of product. Besides, their attitudes engaging with the price of good food items or new ones are also explored. Finally, the remaining ones, consumer confidence, includes five questions of evaluating the confidences in their knowledge, feeling about the food they consumed as well as controlling in this, the safety of Taiwanese food supply alongside the management of Government for food safety issue. Responses of this section are all collected on a series of 5-point scale from $1=$ strongly disagree to $5=$ strongly agree. Those five questions of consumer confidence are also created by the author.

Part 4 assesses Practices or behaviours of students through a couple of independent variables: dining-units selection, label information together with one dependent variable to ask the frequency of eating places in the last moths. Three features are collected on the same series of 5-point scale with $1=0 \%, 2=25 \%, 3=50 \%, 4=$ $75 \%$ and $5=100 \%$. The dependent factor is measured by asking: "How often did you eat at the following venues last month?". To aid in the interpretation of the data analysis, this dependent factor is recorded as $0 \%=n e v e r$, $25 \%=$ rarely, $50 \%=$ occasionally, $75 \%=$ frequently, $100 \%=$ very frequently. The factor of dining-units selections is asked the level of nine given criteria, which customers decide to where to eat in reality. Two first factors are taken from the Food \& You survey 2010 in the UK. Ultimately, the last feature, label information, 
Dong, T. T. M., \& Ching, G. S.

consists of seven questions designed by 2013 Food \& health survey of International Food Information Council Foundation. It examines which information on the package consumers usually look at when deciding to purchase food items.

\subsection{Participants}

The socio-demographic characteristics for 369 respondents are showed in table 1. Approximately three-quarters of participants are female's students (70.5\%) and male respondents account for less than one third (29.5\%). Percentages of freshman, sophomore, junior and senior are $38.2 \%, 16.3 \%, 24.4 \%$ and $21.1 \%$ respectively.

\section{Table 1}

Demographic characteristics of respondents

\begin{tabular}{|c|c|c|c|}
\hline & Variables & Frequency (n) & Percent (\%) \\
\hline \multirow[t]{3}{*}{ Gender } & & 369 & 100 \\
\hline & Male & 109 & 29.5 \\
\hline & Female & 260 & 70.5 \\
\hline \multirow[t]{5}{*}{ Year-grade } & & 369 & 100 \\
\hline & Freshman & 141 & 38.2 \\
\hline & Sophomore & 60 & 16.3 \\
\hline & Junior & 90 & 24.4 \\
\hline & Senior & 78 & 21.1 \\
\hline \multicolumn{4}{|c|}{ Have you ever had food-borne illness or heard about anybody suffering it? } \\
\hline & Yes & 99 & 26.8 \\
\hline & No & 270 & 73.2 \\
\hline \multicolumn{4}{|c|}{ If "Yes", where most likely? (multiple choices) } \\
\hline & Home & 15 & 4.1 \\
\hline & Canteens of school & 55 & 14.9 \\
\hline & Street food vendors & 65 & 17.6 \\
\hline & Restaurants & 51 & 13.8 \\
\hline & Leisure facilities & 10 & 2.7 \\
\hline \multicolumn{4}{|c|}{ How much do you spend for monthly food-consumption? } \\
\hline & $\leq 2000 \mathrm{NT}$ & 77 & 20.9 \\
\hline & $2001-3000 \mathrm{NT}$ & 117 & 31.7 \\
\hline & $3001-4000 \mathrm{NT}$ & 75 & 20.4 \\
\hline & $4001-5000 \mathrm{NT}$ & 40 & 10.9 \\
\hline & $>5000 \mathrm{NT}$ & 59 & 16.1 \\
\hline
\end{tabular}

Responses in question of foodborne illness experiences exhibited 99 out of 369 people having such experiences. It means in around one out of four individuals had suffered foodborne illness before or hear about someone catching it in the past. Therein, majority of respondents assume that they got this disease from street food vendors at $17.6 \%$, canteens of school at $14.9 \%$ and restaurants at $13.8 \%$ in overall. Additionally, towards the question of monthly spending for food, about a fifth of students $(20.9 \%)$ spend less than 2000NT and more than a half of students $(52.11 \%$ ) expend around 2001-4000NT on food consuming each month. Besides, monthly expenditures on food consuming of a few students are among 4001-5000NT (10.9\%) or more than 5000NT (16.1\%).

\section{Findings}

\subsection{Dependent factors}

There is one dependent factor which is labeled "eating frequency" in Practice section. This factor aims to discover the eating frequency in different eating venues during last months, including five options: at home, canteens of school, food vendors (in markets or night markets), restaurants as well as the leisure facilities (such 
A case study on the food safety issues of college students in Taiwan

as theme parks, cinema, bowling alley, etc.). The eating frequency at selected venues during last month is illustrated in table 2 .

\section{Table 2}

The eating frequency at given dining-units last month

\begin{tabular}{lccccccc}
\hline & $n$ & Mean & $\begin{array}{c}0 \% \\
\text { (Never) }\end{array}$ & $\begin{array}{c}25 \% \\
\text { (Rarely) }\end{array}$ & $\begin{array}{c}50 \% \\
\text { (Occasionally) }\end{array}$ & $\begin{array}{c}75 \% \\
\text { (Frequently) }\end{array}$ & $\begin{array}{c}100 \% \\
\text { (Very Frequently) }\end{array}$ \\
\hline At home & 369 & 3.12 & 1.6 & 28.7 & 31.4 & 32.0 & 6.2 \\
At canteens & 369 & 3.16 & 2.7 & 19.0 & 41.7 & 32.5 & 4.1 \\
At vendors & 369 & 2.95 & 1.4 & 33.3 & 37.1 & 25.5 & 2.7 \\
At restaurants & 369 & 2.92 & 2.2 & 33.1 & 37.4 & 25.2 & 2.2 \\
At leisure facilities & 369 & 2.60 & 8.1 & 38.8 & 38.5 & 14.4 & 0.3 \\
\hline
\end{tabular}

The results describe that college students mostly ate in canteens (scoring 3.16 in mean scale) and at home (mean value is 3.12). In more detail, the highest rate in very frequently is at home (6.2\%), whilst the rates of eating at home and at canteens in frequently level are the largest with $32 \%$ and $32.5 \%$, respectively. In addition, $41.7 \%$ was the largest in occasionally eating at canteens. Moreover, for food vendors and restaurants, there are approximately $33 \%$ in rarely eating, $37 \%$ in occasionally and even $25 \%$ in frequently of responding. Besides, $8.1 \%$ answered never eating at leisure facilities meanwhile around $77 \%$ rated they ate at such venues in $25 \%$ or $50 \%$ of frequency percent.

As far as the dependent factor is concerned, the comparisons in two groups of gender (Male vs. Female) plus several groups of monthly food spending are also investigated in this part, in order to explore the discrepancies of those groups among the categories of where-to-eat frequency. From table 3, it can be seen that there is a significant difference between male and female in the frequency of eating at food vendors $(\mathrm{Ms}=3.09$ vs. 2.89 , $\mathrm{t}$ $(369)=2.066, p=0.04)$. It suggests that both genders have the same regularity in eating at home, canteens of schools as well as leisure facilities, but an exception is found in eating at street food vendors where male ate more regular than female.

Table 3

The eating frequency differences (at given dining-units) between Male and Female

\begin{tabular}{|c|c|c|c|c|c|}
\hline & & \multicolumn{2}{|c|}{ Gender } & \multirow[b]{2}{*}{$t$} & \multirow[b]{2}{*}{$p$} \\
\hline & & $\begin{array}{c}\text { Male } \\
(\mathrm{n}=109)\end{array}$ & $\begin{array}{c}\text { Female } \\
(\mathrm{n}=260)\end{array}$ & & \\
\hline \multirow{2}{*}{ At home } & Mean & 3.00 & 3.18 & \multirow{2}{*}{-1.659} & \multirow{2}{*}{0.099} \\
\hline & $\mathrm{SD}$ & 0.92 & 0.96 & & \\
\hline \multirow{2}{*}{ At canteens } & Mean & 3.07 & 3.20 & \multirow{2}{*}{-1.273} & \multirow{2}{*}{0.204} \\
\hline & $\mathrm{SD}$ & 0.87 & 0.87 & & \\
\hline \multirow{2}{*}{ At vendors } & Mean & 3.09 & 2.89 & \multirow{2}{*}{2.066} & \multirow{2}{*}{$0.040^{*}$} \\
\hline & $\mathrm{SD}$ & 0.81 & 0.88 & & \\
\hline \multirow{2}{*}{ At restaurants } & Mean & 2.94 & 2.91 & \multirow{2}{*}{0.337} & \multirow{2}{*}{0.736} \\
\hline & $\mathrm{SD}$ & 0.87 & 0.87 & & \\
\hline \multirow{2}{*}{ At leisure facilities } & Mean & 2.65 & 2.58 & \multirow{2}{*}{0.775} & \multirow{2}{*}{0.439} \\
\hline & $\mathrm{SD}$ & 0.82 & 0.85 & & \\
\hline
\end{tabular}

Note. $* p<0.05$

As can be seen from table 4, there are significant differences among five groups of monthly food spending, including less than 2000NT $(\mathrm{n}=77), 2001-3000 \mathrm{NT}(\mathrm{n}=117), 3001-4000(\mathrm{n}=75), 40001-5000(\mathrm{n}=40)$ and more than 5000NT $(\mathrm{n}=59)$ in the frequency of eating at home $(\mathrm{F}=14.045, p=0.000)$, eating at food vendors $(\mathrm{F}$ $=4.006, p=0.003)$ and eating at restaurants $(\mathrm{F}=3.635, p=0.006)$. After observing the discrepancies among these groups, the Post Hoc tests are analyzed in the purposes of pointing out the exactly differences in every group with each other.

Based on the outcomes of Post Hoc tests, it can be concluded that for those spending less than 2000NT ate at 
Dong, T. T. M., \& Ching, G. S.

home more frequently than those spending over this amount of money for food. More precisely, students who pay 2001-3000NT per month for food consumption ate at home more regularly than students pay from 4001 to $5000 \mathrm{NT}$; and for those who have monthly food spending of 3001-4000NT frequently ate at home than those having monthly food spending of over 5000NT. Next is the regular rate of eating at food vendors, it is founded that participants spending in two ranges of spending: 2001-300NT and 4001-5000NT ate at vendors more often than participants who expending less than 2000NT each month. Ultimately, the group of less than 2000NT in spending also ate at restaurant much less than the group of spending more than 5000NT for food per month.

Table 4

The eating frequency in various dining-venues among groups of different monthly spending on food consumption

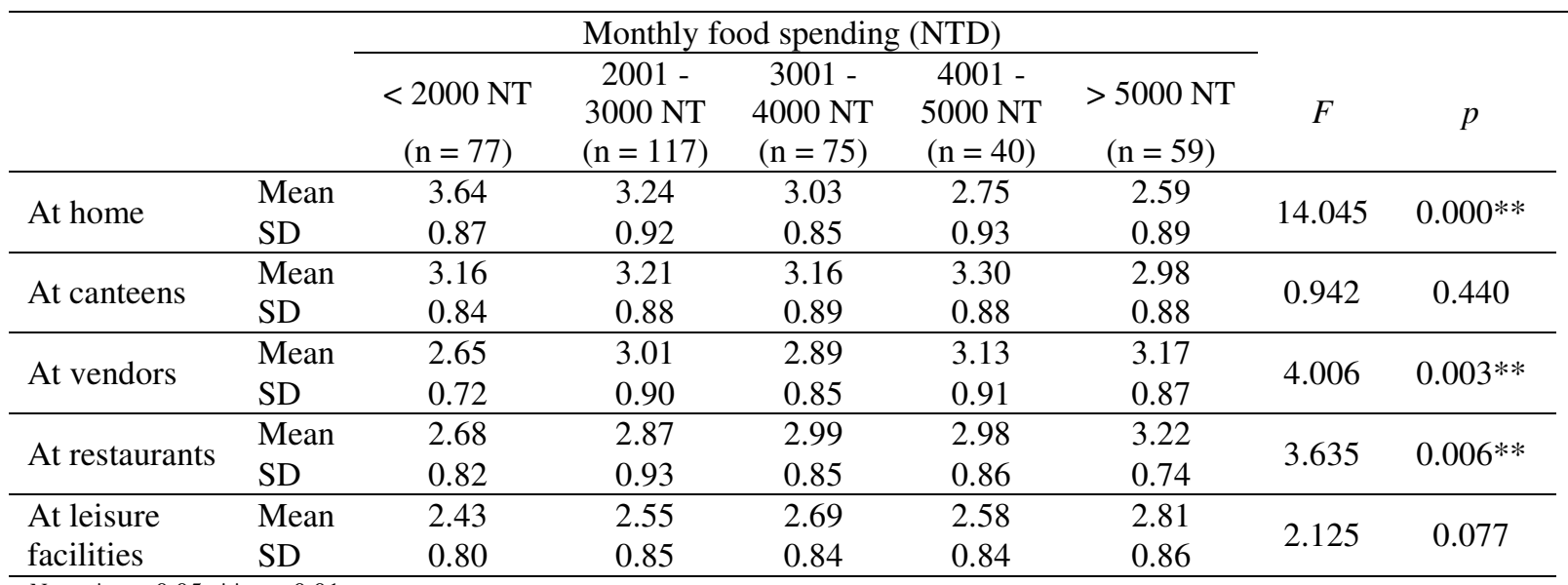

Note. $* p<0.05 ; * * p<0.01$

\subsection{Reliability, Mean and Standard deviation (SD)}

This part is started by investigating the reliability of current study. The overall Cronbach's alpha of whole study is 0.90 with 55 question items belong to three dimensions, and the valid is $\mathbf{9 8 . 6 \%}$ (1.4\% missing data). Following on from this, table 5 and 6 reports reliability, mean and standard deviation (SD) of each construct as well as all question items.

\section{Table 5}

Reliability, mean and standard deviation of dimensions and factors

\begin{tabular}{lccccc}
\hline & $n$ & Number of items & Mean & SD & Cronbach's $\alpha$ \\
\hline KNOWLEDGE & $\mathbf{3 6 7}$ & $\mathbf{2 1}$ & $\mathbf{3 . 3 4}$ & $\mathbf{0 . 4 7}$ & $\mathbf{0 . 8 5}$ \\
General knowledge & 368 & 9 & 3.09 & 0.71 & 0.89 \\
Information sources & 369 & 6 & 3.26 & 0.56 & 0.70 \\
Responsibility awareness & 368 & 6 & 3.79 & 0.70 & 0.80 \\
\hline ATTITUDE & $\mathbf{3 6 8}$ & $\mathbf{1 3}$ & $\mathbf{2 . 8 6}$ & $\mathbf{0 . 3 8}$ & $\mathbf{0 . 7 7}$ \\
Organic food & 368 & 4 & 3.02 & 0.55 & 0.71 \\
Willingness to pay & 368 & 4 & 2.94 & 0.48 & 0.60 \\
Consumer confidence & 369 & 5 & 2.67 & 0.57 & 0.79 \\
\hline PRACTICE & $\mathbf{3 6 7}$ & $\mathbf{1 6}$ & $\mathbf{3 . 6 7}$ & $\mathbf{0 . 5 0}$ & $\mathbf{0 . 8 6}$ \\
Dining-unit selection & 368 & 9 & 3.89 & 0.51 & 0.80 \\
Information label & 367 & 7 & 3.42 & 0.70 & 0.85 \\
\hline
\end{tabular}

As shown in table 5 the Cronbach's alpha of Knowledge dimension is 0.85, Attitude is 0.77, and Practice is 0.86. It shows that all three constructs in the current are reliable. Alongside these dimensions, most of factors are proven that their data scales are trustworthy, above 0.70 of Cronbach's alpha. Organic food factor produces reliability value of 0.6 , and it ranges in acceptable level.

In general, Practice dimension has the highest value of mean at $3.67(\mathrm{SD}=0.86)$, Knowledge follows with 
A case study on the food safety issues of college students in Taiwan

the mean of $3.34(\mathrm{SD}=0.47)$ and the last is Attitude dimension at $2.86(\mathrm{SD}=0.38)$. These values point out that although the mean score is still above the average, the responding in Attitude dimension is not too positive to compare with Knowledge and Practice dimension. Furthermore, Practice dimension is perceived as more positive responding than Knowledge dimension.

The calculation of eight factors is also demonstrated in table 5. As can be seen from above table, two factors belong to Practice dimension (dining-unit selections, label information) and three factors lies in Knowledge dimension (general knowledge, information sources, responsibility awareness) have higher values of mean than maintaining factors (organic food, willingness-to-pay, consumer confidence) of Attitude section, in general. More precisely, "dining-unit selection" factor have the highest mean score at $3.89(\mathrm{SD}=0.51)$, the second is responsibility awareness at $3.79(\mathrm{SD}=0.70)$. Factor named "label information" follows with mean value of 3.42 $(\mathrm{SD}=0.70)$. Next is "information sources" at $3.26(\mathrm{SD}=0.56)$. Two factors labeled "general knowledge" and "organic food" have mean scores of 3.09 (SD = 0.71) and 3.02 (SD = 0.55), in turn. Subsequently, willingness-to-pay which is one of two factors in lowest score group has the value at $2.94(\mathrm{SD}=0.48)$. Eventually, the factor has the lowest score is consumer confidence, at 2.86 ( $\mathrm{SD}=0.57)$.

Table 6

Mean and standard deviation of all question items

\begin{tabular}{|c|c|c|c|c|}
\hline \multirow{2}{*}{\multicolumn{2}{|c|}{ 1. KNOWLEDGE }} & $n$ & Mean & $S D$ \\
\hline & & 367 & 3.34 & 0.47 \\
\hline \multicolumn{2}{|c|}{ A. General knowledge } & 368 & 3.09 & 0.71 \\
\hline 1 & The danger of pesticides residues in food & 369 & 2.42 & 0.87 \\
\hline 2 & The danger of chemical preservatives in food & 369 & 3.42 & 0.97 \\
\hline 3 & The danger of food additives and artificial colors & 369 & 3.59 & 0.96 \\
\hline 4 & Vitamin content of processed food & 368 & 3.05 & 0.93 \\
\hline 5 & Fat or cholesterol content of specific food & 369 & 3.37 & 1.00 \\
\hline 6 & Foodborne illness from bacteria & 369 & 2.86 & 1.07 \\
\hline 7 & Microbiological contamination of fresh food & 369 & 2.90 & 1.04 \\
\hline 8 & The danger of genetically modified food & 369 & 2.98 & 1.04 \\
\hline 9 & The safety of organic food & 369 & 3.26 & 0.92 \\
\hline \multicolumn{2}{|c|}{ B. Information sources } & 369 & 3.26 & 0.56 \\
\hline 10 & Trusted friends & 369 & 3.40 & 0.84 \\
\hline 11 & Family members & 369 & 3.95 & 0.86 \\
\hline 12 & Health professionals & 369 & 4.16 & 0.82 \\
\hline 13 & Food manufacturers & 369 & 2.58 & 0.86 \\
\hline 14 & The Media & 369 & 2.72 & 0.91 \\
\hline 15 & The Government & 369 & 2.73 & 1.01 \\
\hline \multicolumn{2}{|c|}{ C. Responsibility awareness } & 368 & 3.79 & 0.70 \\
\hline 16 & Consumers & 368 & 3.06 & 1.13 \\
\hline 17 & Farmers & 368 & 3.57 & 1.03 \\
\hline 18 & Food industry & 369 & 4.41 & 0.77 \\
\hline 19 & The Government & 369 & 4.46 & 0.77 \\
\hline 20 & The academia & 368 & 3.58 & 1.05 \\
\hline 21 & The media & 368 & 3.64 & 1.08 \\
\hline \multicolumn{2}{|c|}{ 2. ATTITUDE } & 368 & 2.86 & 0.38 \\
\hline \multicolumn{2}{|c|}{ A. Organic product } & 368 & 3.02 & 0.55 \\
\hline 1 & Organic products are healthier & 369 & 3.29 & 0.80 \\
\hline 2 & Organic products have superior quality & 369 & 3.33 & 0.75 \\
\hline 3 & Organic products are tastier & 368 & 2.81 & 0.69 \\
\hline 5 & Organic products are in fashion & 368 & 2.67 & 0.76 \\
\hline \multicolumn{2}{|c|}{ B. Willingness-to-pay } & 368 & 2.94 & 0.48 \\
\hline 6 & Quality foods (e.g. organic food) have reasonable price & 368 & 2.39 & 0.71 \\
\hline 7 & I prefer to buy quality food (e.g. organic food) & 368 & 2.93 & 0.61 \\
\hline 8 & I am constantly paying for sampling new foods & 368 & 3.29 & 0.75 \\
\hline 9 & The price is not matter with good quality & 368 & 3.16 & 0.77 \\
\hline
\end{tabular}


Table 6 ... continued

\begin{tabular}{|c|c|c|c|c|}
\hline & & $n$ & Mean & $S D$ \\
\hline \multicolumn{2}{|c|}{ C. Consumer confidence } & 369 & 2.67 & 0.57 \\
\hline 10 & Confident about my knowledge in food safety & 369 & 2.78 & 0.73 \\
\hline 11 & The food which I consume is safe & 369 & 2.81 & 0.77 \\
\hline 12 & I try to control the food safety issue so much & 369 & 2.91 & 0.68 \\
\hline 13 & Confident about the safety of Taiwanese food supply & 369 & 2.54 & 0.80 \\
\hline 14 & Confident about the management of Government & 369 & 2.32 & 0.88 \\
\hline \multicolumn{2}{|c|}{ 3. PRACTICE } & 367 & 3.63 & 0.50 \\
\hline \multicolumn{2}{|c|}{ B. Dining-units selection } & 368 & 3.80 & 0.49 \\
\hline 6 & Cleanliness and hygiene & 368 & 4.15 & 0.74 \\
\hline 7 & Familiarity & 368 & 3.66 & 0.86 \\
\hline 8 & Tasty dishes & 368 & 4.10 & 0.75 \\
\hline 9 & Reasonable prices & 368 & 4.07 & 0.73 \\
\hline 10 & Healthy food choices & 368 & 3.61 & 0.87 \\
\hline 11 & Convenience & 368 & 3.85 & 0.77 \\
\hline 12 & Promotion & 368 & 3.02 & 0.88 \\
\hline 13 & Going with family members & 368 & 3.78 & 0.83 \\
\hline 14 & Going with friends & 368 & 3.92 & 0.71 \\
\hline \multicolumn{2}{|c|}{ C. Label information } & 367 & 3.42 & 0.70 \\
\hline 15 & Expiration date & 368 & 4.38 & 0.83 \\
\hline 16 & Natural/ organic advertisement & 368 & 3.07 & 0.93 \\
\hline 17 & Brand names & 368 & 3.36 & 0.97 \\
\hline 18 & Cooking instruction/ preparation time & 368 & 3.39 & 1.00 \\
\hline 19 & Nutrition benefits & 367 & 3.33 & 0.98 \\
\hline 20 & Health benefits & 368 & 3.19 & 0.99 \\
\hline 21 & Country of origin labeling & 368 & 3.20 & 1.06 \\
\hline
\end{tabular}

In general knowledge factor, students give their self-evaluated knowledge scores in nine variables of specific issues. The group having the highest mean values in their general knowledge includes in the danger of food additives and artificial colors (3.59), the danger of chemical preservatives in food (3.42), fat or cholesterol content of specific food (3.37), the safety of organic food (3.26) and vitamin content of processed food (3.05). In contrast, they assess their knowledge is not too high in a group consists comprehends of the danger of genetically modified food (2.98), microbiological contamination of fresh food (2.90), foodborne illness from bacteria (2.86), and especially in the danger of pesticides residues in food with the lowest score at 2.42. The major factors influencing food safety are improper use of pesticides, hormones, additives and preservatives in food production. Importantly, Taiwan uses $17 \mathrm{~kg}$ pesticides per hectare; and it is still reported the increased numbers in situations that pesticide residues in food and beverage. The results, however, show Taiwanese students do not have much knowledge in the danger of pesticides in food.

Information sources factor facilitates the observation on how respondents collect food safety news through six given information sources (trusted friends, family members, health professionals, food manufacturers, the information on media, and the Government). Consumers rate the information of food safety from health professionals (e.g., doctor, nurse, and dietitian) as the most trustworthy source (4.16). Besides, they found their family members are reliable, as the second source (3.95) to achieve food safety information in this factor. Additionally, information about food safety shared from friends is also considered as the third reliable source in order to obtain such information. Interestingly, the media (such as television, radio, newspaper, internet, etc.) seems to be the most popular sources disseminating information or news to everyone, however, this type of source is not too much positive to reach the believes of Taiwanese consumers in current study, based on their evaluations in the mean value of 2.72. Similarly, neither the government can touch consumers' believes as a trustworthy source of this information, at the mean value in 2.73 which is approximately same with the media. Lastly, information provided by food manufacturers is perceived to be the least trustworthy source (2.58). It can be discussed that, in the process of obtaining food safety information, consumers in Taiwan are more counting on those who have professional or advanced knowledge as doctors/ dietitians, alongside with those they have 
closed-relationships as their family members or trusted friends, instead of getting such information from food manufacturers, the media or the government.

In responsibility awareness factor, respondents are questioned to assess the responsibility in five given options following their perspectives. Whereby, they are aware of the government and food industry need to have the principal responsibilities in food safety issue with the mean of 4.46 and 4.41 , respectively. Besides, in the viewpoints of consumers, the media, the academia and farmers also share the high scores engaging in food safety responsibilities; mean values of three agencies in turn are 3.64, 3.58 and 3.57. Regarding responsibility of ensuring food safety, consumers consider they are not responsible to handle this issue as much as others, with the lowest mean score at 3.06 .

Factor of organic product examines consumers' attitude as well as their thoughts towards this type of products in four question items, containing the statements of its characteristics such as healthier, tastier, superior quality, and "in fashion". Most of the consumers declared that organic products have superior quality (3.33) along with organic food are healthier (3.29). Although they agree with the perceptions that this type of food has some beneficial features, as discussing above, they do not feel this product is tastier (2.81). Finally, the statement of "organic products are in fashion" has the lowest value of mean score at 2.67.

In attitude towards willingness to pay factor, this factor consists of four variables relating to this feature. The outcomes point out that consumers evaluate their attitude for the statement of "constantly paying for sampling new foods" is the highest value, at 3.29. It means that consumers have tendency to be attracted by new foods and be willing to constantly pay for try these food items. Furthermore, although the majority of respondents have positive attitudes on "the price is not matter with good quality" (mean value is 3.16), they also express a minority of their agreements in "quality foods (e.g. organic food) have reasonable price" (2.39 of mean score). However, participants still declare a little positive attitude in "prefer to buy quality food (e.g. organic food)", equaling to 2.93).

In consumer confidence factor, five question items are established to this feature, in order to discover the confidence of consumers in their knowledge, in their feeling about the safe of food consumption, their handling of food safety issue as well as in the safety of Taiwanese food supply and the management of government. Whereby, respondents are much more confident in their handling in the issue of food safety (2.91), in their knowledge related to this issue (2.78) as well as being confident in the safety of food that they consume (2.81) to compare with their extents of confidence in the safety of Taiwanese food supply (2.54), especially in the management of government (2.32).

In dining-unit selection factor, this is a set of nine criteria which consumers determine the influences of these variances to their behaviors in choosing where-to-eat. This factor receives the highest score to compare with others; it is proven for the positive in students' behaviors, particularly in their dining-units decisions. The most preferred criteria they choose are the cleanliness and hygiene of dining-units (4.15) as important as the food stores in general have tasty dishes (4.10) and reasonable prices (4.07). Following the first group, going with friends (3.78) becomes an influence on their decisions, perhaps they choose some venues to eat because they are interested in hanging out with their friends. Moreover, convenience (3.85) and going with family (3.78) also contribute to affect their choices. If the location of dining-units is convenient for students, such as location near schools or on campus provide much easier access for students to have lunch or dinner without traveling far. Time convenience is also a reason for their where-to-eat decisions; because there are those days their timetable is tight to have enough eating-time. Next, respondents responds "at home" as where they frequently eat with the mean value of 3.66. Furthermore, "healthy food choices" followed by the familiarity with mean score of 3.61. Finally, participants are also affected by the promotion of eating venues with 3.02 of mean value. However, the impact of promotion is not as much as other criteria. It means that to the promotion of the food stores seems the ultimate effect on their choices although students still pay attention to it.

Label information factor aims to explore consumers' behaviors towards information on the packages which 
Dong, T. T. M., \& Ching, G. S.

they look for in order to purchase or consume food products. There are seven standards given in this factor. It has been found that "expiration date" is a factor that consumers concern the most through the highest mean score at 4.38. With regards to all variables of this factor, expiration date outclasses the mean scores of remaining information. It proves, therefore, that consumers especially pay their attention to it; or expiration date is still the most familiar information on package for students so they always consider this as the first variable looking for. The next ones involve information of "cooking instruction/ preparation time", "brand names", and "nutrition benefits" by the mean value of 3.39, 3.36 and 3.33 respectively. Subsequently, respondents in turn evaluate their information references on "country of origin labeling" and "health benefits" as 3.20 and 3.19. Lastly, the advertisement of natural or organic food in package just account for the mean score of 3.07, as the lowest information-concern of consumers in this feature.

4.3 T-test

Table 7

T-test for Gender group

\begin{tabular}{|c|c|c|c|c|c|}
\hline & & \multicolumn{2}{|c|}{ Gender } & \multirow[b]{2}{*}{$t$} & \multirow[b]{2}{*}{$p$} \\
\hline & & $\begin{array}{c}\text { Male } \\
(n=108)\end{array}$ & $\begin{array}{c}\text { Female } \\
(\mathrm{n}=258)\end{array}$ & & \\
\hline \multirow{2}{*}{ KNOWLEDGE } & Mean & 3.31 & $\mathbf{3 . 3 5}$ & \multirow{2}{*}{-0.613} & \multirow{2}{*}{0.540} \\
\hline & SD & 0.47 & 0.48 & & \\
\hline \multirow{2}{*}{ General knowledge } & Mean & 3.13 & 3.08 & \multirow{2}{*}{0.654} & \multirow{2}{*}{0.513} \\
\hline & SD & 0.66 & 0.73 & & \\
\hline \multirow{2}{*}{ Information sources } & Mean & 3.16 & 3.30 & \multirow{2}{*}{-2.181} & \multirow{2}{*}{$0.030 *$} \\
\hline & SD & 0.60 & 0.53 & & \\
\hline \multirow{2}{*}{ Responsibility awareness } & Mean & 3.74 & 3.81 & \multirow{2}{*}{-0.864} & \multirow{2}{*}{0.388} \\
\hline & SD & 0.68 & 0.70 & & \\
\hline \multirow{2}{*}{ ATTITUDE } & Mean & 2.89 & 2.85 & \multirow{2}{*}{0.782} & \multirow{2}{*}{0.435} \\
\hline & SD & 0.41 & 0.37 & & \\
\hline \multirow{2}{*}{ Organic food } & Mean & 3.04 & 3.02 & \multirow{2}{*}{0.335} & \multirow{2}{*}{0.738} \\
\hline & SD & 0.59 & 0.53 & & \\
\hline \multirow{2}{*}{ Willingness to pay } & Mean & 3.01 & 2.91 & \multirow{2}{*}{1.797} & \multirow{2}{*}{0.073} \\
\hline & SD & 0.52 & 0.46 & & \\
\hline \multirow{2}{*}{ Consumer confidence } & Mean & 2.67 & 2.67 & \multirow{2}{*}{-0.103} & \multirow{2}{*}{0.918} \\
\hline & SD & 0.59 & 0.56 & & \\
\hline \multirow{2}{*}{ PRACTICE } & Mean & 3.54 & 3.67 & \multirow{2}{*}{-2.211} & \multirow{2}{*}{$0.028 *$} \\
\hline & SD & 0.45 & 0.51 & & \\
\hline \multirow{2}{*}{ Dining-unit selections } & Mean & 3.71 & 3.83 & \multirow{2}{*}{-2.119} & \multirow{2}{*}{$0.035^{*}$} \\
\hline & SD & 0.50 & 0.49 & & \\
\hline \multirow{2}{*}{ Information label } & Mean & 3.32 & 3.46 & -1677 & 0,094 \\
\hline & SD & 0.62 & 0.72 & & 0.094 \\
\hline
\end{tabular}

The above table shows the significant differences between males and females in information sources $(\mathrm{Ms}=$ 3.16 vs. $3.30, \mathrm{t}(367)=-2.181, \mathrm{p}=0.030)$, practice dimension $(\mathrm{Ms}=3.54$ vs. 3.67, $\mathrm{t}(367)=-2.211, \mathrm{p}=0.028)$ which is caused by the difference in dining-unit selection $(\mathrm{Ms}=3.71$ vs. 3.83, $\mathrm{t}(367)=-2.119, \mathrm{p}=0.035)$. Following these results, it can be concluded that:

$>$ Females are observed to be more convinced by information sources of food safety than males.

$>\quad$ Females are more positive in practice towards food safety than males.

$>$ Females are more careful in dining-unit selections than males. 
A case study on the food safety issues of college students in Taiwan

Table 8

T-test for Foodborne-illness experiences group

\begin{tabular}{|c|c|c|c|c|c|}
\hline & & Food & llness & & \\
\hline & & $\begin{array}{c}\text { YES } \\
(n=99)\end{array}$ & $\begin{array}{c}\text { NO } \\
(n=270)\end{array}$ & $t$ & $p$ \\
\hline KNOWIFDCF & Mean & 3.36 & 3.33 & 0530 & 0500 \\
\hline KNOWLEDGE & SD & 0.42 & 0.49 & 0.539 & 0.590 \\
\hline Genorollknoullador & Mean & 3.13 & 3.08 & & \\
\hline General knowledge & SD & 0.70 & 0.71 & 0.664 & 0.507 \\
\hline & Mean & 3.29 & 3.25 & & \\
\hline Information sources & SD & 0.58 & 0.55 & 0.624 & 0.533 \\
\hline & Mean & 3.79 & 3.78 & 0063 & \\
\hline Responsibility awareness & SD & 0.66 & 0.71 & 0.063 & 0.950 \\
\hline ATTITUDF & Mean & 2.85 & 2.87 & $0=25$ & 0502 \\
\hline ATTTTUDE & SD & 0.38 & 0.38 & -0.535 & 0.593 \\
\hline Orcanis food & Mean & 3.04 & 3.02 & 0237 & 0812 \\
\hline Organic 1000 & SD & 0.55 & 0.55 & 0.251 & 0.015 \\
\hline Willinoness to nay & Mean & 2.97 & 2.93 & 0778 & 0437 \\
\hline wimmgness to pay & SD & 0.48 & 0.48 & & \\
\hline & Mean & 2.59 & 2.70 & & \\
\hline Consumer contidence & SD & 0.56 & 0.57 & -1.651 & 0.100 \\
\hline PDACTICE & Mean & 3.64 & 3.63 & 0204 & \\
\hline PRACTICE & SD & 0.46 & 0.51 & 0.204 & 0.838 \\
\hline Dining _unit selections & Mean & 3.82 & 3.79 & 0545 & 0.586 \\
\hline Dining-unit selections & SD & 0.46 & 0.50 & 0.545 & 0.586 \\
\hline Information lahels & Mean & 3.41 & 3.42 & 0174 & 0862 \\
\hline intormation labels & SD & 0.65 & 0.71 & $-0.1 / 4$ & 0.802 \\
\hline
\end{tabular}

Note. ${ }^{*} p<0.05$

Surprisingly, table above of the T-test for Foodborne illness experience group shows that there is not any significant difference in three dimensions as well as eight factors belong to these dimensions in both groups. However, there is another explanation when observing mean score of single factors:

$>\quad$ Knowledge dimension: those responding "Yes" in the question of "foodborne illness experience" have better knowledge than those responding "No" (Ms = 3.36 vs. 3.33, t $(369)=0.539)$, in which, general knowledge factor is higher $(\mathrm{Ms}=3.13$ vs. $3.08, \mathrm{t}(369)=0.664)$.

$>\quad$ Organic food and willingness-to-pay factor: the attitudes of foodborne illness experience group ("Yes") are more positive than the other one ("No") in two factors. Possible reasons may come from the fact that they want to look for safer food, as organic food (Ms $=3.04$ vs. 3.02, t $(369)=0.237)$ as well as being willing to pay more to get the safety in food consumption $(\mathrm{Ms}=2.97$ vs. $2.93, \mathrm{t}(369)=0.778)$.

$>$ Consumer confidence factor: in contrast, those who have experienced in the food diseases are less confident in food safety issue than those have never $(\mathrm{Ms}=2.59$ vs. 2.70, $\mathrm{t}(369)=-1.651)$.

$>$ Practice dimension: "Yes" group have better behaviours in practice, in which they chose dining-units more cautiously than "No" group $(\mathrm{Ms}=3.82$ vs. $3.79, \mathrm{t}(369)=0.545)$.

Therefore, the above discussion shows both a slight and reasonable difference between two groups of foodborne illness experience. Nevertheless, it is not enough to conclude the significant differences as the results reported. A number of reasons can be given to clarify these results. Firstly, this research has a small sample scale with 369 participants and proportion of those who have experienced with foodborne illness is around one-third. The discrepancies are likely to be found in a larger scope.

Besides, another reason should be considered is the wording in question, "Have you ever had food-borne illness or heard about anybody catching it?" It is possible that respondents answer not only based on their 
Dong, T. T. M., \& Ching, G. S.

personal experiences that they actually get foodborne illness, but also based on that of acquaintances or friends. Consequently, the ratio between their self-experience and their knowing from others is not the exact observation. Due to others' experiences, they do not have explicit knowledge of this issue; additionally, they do not have to suffer this disease, hence their attitudes are not pessimistic, and it leads to their practice is not as vigilant to protect themselves as those suffer. It is a limitation of this paper which further researches should clarify.

Lastly, since the reflection of self-experience from those who used to suffer from foodborne illness could not guide them to proper direction in food consuming, it is a matter of concern. The only possible reason in this case is that students may have insufficient interest in the issue of food safety. Even when they have been got foodborne disease before, but generally, they tend to think it is dangerous enough to have progressive changes in their attitude or behaviour along enhance their knowledge in this matter. This should be the responsibilities of Government, academia and media to educate students in this specific issue.

In questionnaire development, the question of "How much do you spend for food-consume monthly?" includes five options: less than 2000NT, 2001-3000NT, 3001-4000NT, 4001-5000NT and more than 5001NT. Notwithstanding, when five groups are analyzed by ANOVA test, there is not any significant difference in attitude and practice dimension, alongside five factors of organic food, willingness to pay, consumer confidence, dining-units selections and label information. Therefore it is necessary to create a new parameter value to observe whether there was difference under a new parameter setting. It exhibits the significant difference when comparing 4 groups of "less than or equal to 5000NTD spent-per-month" as a whole and the "over 5001NTD spent-per-month" group. Thus, it is arguable to set 5000NTD as a new parameter value to measure given dimensions/ factors.

Table 9

T-test for Monthly food spending group

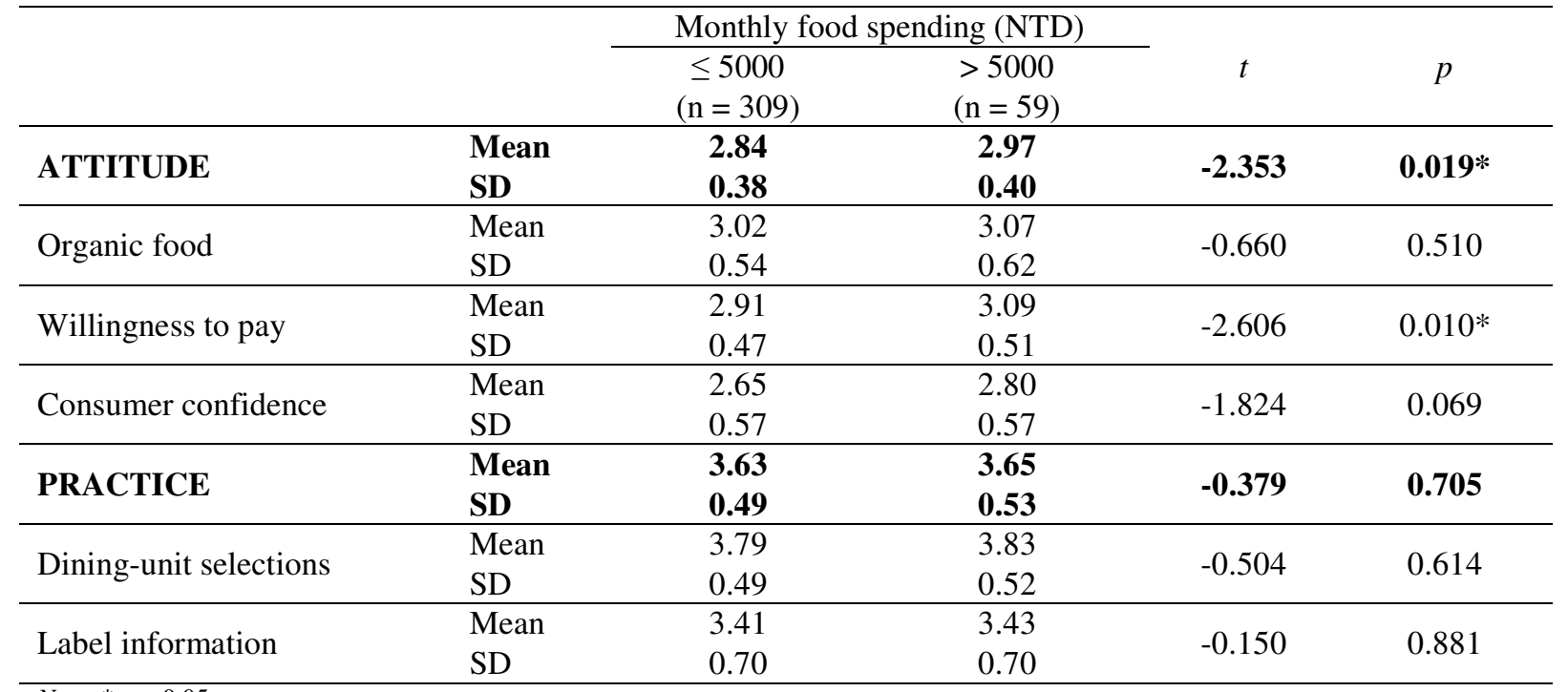

Note. $* p<0.05$

As the results show in table there are significant different between two new groups in Attitude construct (Ms $=2.84$ vs. $2.97, \mathrm{t}(368)=-2.353, \mathrm{p}=0.019)$, especially in willingness-to-pay $(\mathrm{Ms}=2.91$ vs. $3.09, \mathrm{t}(368)=$ $-2.606, \mathrm{p}=0.010)$. Following these results, it can be concluded that:

$>$ Those spending more than 5000NT per month for their food consumption are more positive in attitude towards food safety issues than those spending lower than 5000NT monthly.

$>\quad$ Those spending more than 5000NT per month for their food consumption are more positive in willingness-to-pay towards food safety issues than those spending lower than 5000NT monthly. Therefore, it can be proven that the amount of 5000 NT is the standard that consumer are willing to 
pay in order to get high-quality products.

Due to new parameter value setting (instead of 5 groups of monthly food spending as originally), a T-test of new groups is also analyzed in eating frequency differences at given dining-units, as illustrated in the table 10 . There are significant differences between participants' group expending less than 5000NT monthly and its counterpart, in eating frequency at home $(\mathrm{Ms}=3.22$ vs. $2.59, \mathrm{t}(368)=4.789, p=0.000)$, food vendors $(\mathrm{Ms}=$ 2.91 vs. $3.17, \mathrm{t}(368)=-2.148, p=0.032)$, restaurants $(\mathrm{Ms}=2.86$ vs. 3.22, $\mathrm{t}(368)=-2.917, p=0.004)$, and leisure facilities $(\mathrm{Ms}=2.56$ vs. $2.81, \mathrm{t}(368)=-2.157, p=0.032$ ). The result exposes students paying more than 5000 NT per month for food consume have dined at food vendors, leisure facilities and particularly restaurants, more frequently than students paying less than this amount. In contrast, the former have eaten at home much less frequently than the latter.

To compare with ANOVA test of 5 groups of monthly food spending as originally, it is similar that there is not any significant difference in the eating frequency at canteens between two new groups. It can be concluded though how much students expend on food consuming and how different they have the eating frequency at dining-units among groups of food spending, their eating frequency at school-canteens is still the same.

Table 10

The eating frequency differences (at given dining-units) between two new groups of monthly food spending

\begin{tabular}{|c|c|c|c|c|c|}
\hline & & \multicolumn{2}{|c|}{ Monthly food spending (NTD) } & \multirow[b]{2}{*}{$t$} & \multirow[b]{2}{*}{$p$} \\
\hline & & $\begin{array}{c}\leq 5000 \\
(\mathrm{n}=308)\end{array}$ & $\begin{array}{c}>5000 \\
(n=58)\end{array}$ & & \\
\hline \multirow{2}{*}{ At home } & Mean & 3.22 & 2.59 & \multirow{2}{*}{4.789} & \multirow{2}{*}{$0.000 * *$} \\
\hline & SD & 0.93 & 0.89 & & \\
\hline \multirow{2}{*}{ At canteens } & Mean & 3.19 & 2.98 & \multirow{2}{*}{1.707} & \multirow{2}{*}{0.089} \\
\hline & SD & 0.87 & 0.88 & & \\
\hline \multirow{2}{*}{ At vendors } & Mean & 2.91 & 3.17 & \multirow{2}{*}{-2.148} & \multirow{2}{*}{$0.032 *$} \\
\hline & SD & 0.86 & 0.87 & & \\
\hline \multirow{2}{*}{ At restaurants } & Mean & 2.86 & 3.22 & \multirow{2}{*}{-2.917} & \multirow{2}{*}{$0.004 * *$} \\
\hline & SD & 0.88 & 0.74 & & \\
\hline \multirow{2}{*}{ At leisure facilities } & Mean & 2.56 & 2.81 & \multirow{2}{*}{-2.157} & \multirow{2}{*}{$0.032 *$} \\
\hline & SD & 0.83 & 0.86 & & \\
\hline
\end{tabular}

Note. $* p<0.05 ; * * p<0.01$

\subsection{ANOVA results}

Table 11 reports the significant differences among freshman (140 respondents), sophomore $(\mathrm{n}=59)$, junior $(\mathrm{n}=89)$ and senior $(\mathrm{n}=78)$ in information sources $(\mathrm{F}=3.761, p=0.011)$, attitude dimension $(\mathrm{F}=3.879, p=$ $0.009)$ in which organic food $(\mathrm{F}=4.469, p=0.004)$ and consumer confidence $(\mathrm{F}=3.211, \mathrm{p}=0.023)$ have significant differences and lastly, label information $(\mathrm{F}=2.657, p=0.048)$. After analyzing ANOVA, the Post-hoc tests is used to specifically figure out which among these groups are different to the others in information sources, attitude dimension, organic food, consumer confidence and label information, as follows in table 12.

The Post-hoc comparison using the Turkey HSD test indicates that, in:

$>\quad$ Information sources factor: the mean score for freshman group $(\mathrm{M}=3.29, \mathrm{SD}=0.57)$ is significantly different from junior group $(\mathrm{M}=3.09, \mathrm{SD}=0.58)$, and senior group $(\mathrm{M}=3.36, \mathrm{SD}=0.52)$ is also significantly different from junior group.

$>$ Attitude dimension: the mean score for senior group $(\mathrm{M}=2.97, \mathrm{SD}=0.41)$ is significantly different from sophomore group $(\mathrm{M}=2.79, \mathrm{SD}=0.34)$, and senior group is significantly different from junior group $(\mathrm{M}=2.80, \mathrm{SD}=0.41)$. 
$>$ Organic food factor: the mean score for freshman group $(\mathrm{M}=3.09, \mathrm{SD}=0.52)$ is significantly different from junior group $(\mathrm{M}=2.87, \mathrm{SD}=0.53)$, and senior group $(\mathrm{M}=3.13, \mathrm{SD}=0.64)$ is significantly different from junior group.

$>\quad$ Consumer confidence factor: the mean score for senior group $(\mathrm{M}=2.83, \mathrm{SD}=0.56)$ is significantly different from sophomore group $(\mathrm{M}=2.54, \mathrm{SD}=0.51)$.

$>\quad$ Label information factor: the mean score for senior group $(\mathrm{M}=3.61, \mathrm{SD}=0.74)$ is significantly different from freshman group $(\mathrm{M}=3.36, \mathrm{SD}=0.67)$.

The results obtained denote that seniors are much more significant differences than students of other year-grades. The group of seniors is counting more on sources of safe food information. Moreover, respondents who are the last year students are considered more mature individuals; hence, the more experienced they are the more positive are their attitudes $(p<0.01)$. It is also compatible with their confidence and especially in their attitudes towards organic food $(p<0.01)$. In references of label information, furthermore, seniors' behaviors are more progressive than group of sophomores, juniors or freshmen. In spite of these significant discrepancies, there is not any significant difference shown in knowledge as well as practice section among four groups of year-grade. In essence, last year students would be normally expected that their knowledge and practice are better than students of other year-grades. From this result, obviously, seniors' group has significant difference comparing others' group neither in Knowledge nor Practice section, but in Attitude section (particularly in attitude towards organic food). Besides, apart senior students, freshmen are also positive in their attitudes toward organic food. It can be explained that the youngest persons in college, freshmen, is optimistic in approaching new food or new food trends.

Table 11

ANOVA for Year-grade group

\begin{tabular}{|c|c|c|c|c|c|c|c|}
\hline & & \multicolumn{4}{|c|}{ Year-grade } & \multirow[b]{2}{*}{$F$} & \multirow[b]{2}{*}{$p$} \\
\hline & & $\begin{array}{l}\text { Freshman } \\
(\mathrm{n}=140)\end{array}$ & $\begin{array}{c}\text { Sophomore } \\
(\mathrm{n}=59)\end{array}$ & $\begin{array}{c}\text { Junior } \\
(\mathrm{n}=89)\end{array}$ & $\begin{array}{c}\text { Senior } \\
(\mathrm{n}=78)\end{array}$ & & \\
\hline \multirow{2}{*}{ KNOWLEDGE } & Mean & 3.28 & 3.34 & 3.35 & 3.42 & \multirow{2}{*}{1.565} & \multirow{2}{*}{0.198} \\
\hline & SD & 0.45 & 0.46 & 0.51 & 0.47 & & \\
\hline \multirow{2}{*}{ General knowledge } & Mean & 3.02 & 3.07 & 3.17 & 3.16 & \multirow{2}{*}{1.195} & \multirow{2}{*}{0.311} \\
\hline & SD & 0.68 & 0.79 & 0.71 & 0.70 & & \\
\hline \multirow{2}{*}{ Information sources } & Mean & 3.29 & 3.30 & 3.09 & 3.36 & \multirow{2}{*}{3.761} & \multirow{2}{*}{$0.011 *$} \\
\hline & SD & 0.57 & 0.51 & 0.58 & 0.52 & & \\
\hline \multirow{2}{*}{ Responsibility awareness } & Mean & 3.66 & 3.83 & 3.87 & 3.87 & \multirow{2}{*}{2.523} & \multirow{2}{*}{0.058} \\
\hline & SD & 0.72 & 0.65 & 0.67 & 0.69 & & \\
\hline \multirow{2}{*}{ ATTITUDE } & Mean & 2.88 & 2.79 & 2.80 & 2.97 & \multirow{2}{*}{3.879} & \multirow{2}{*}{$0.009 * *$} \\
\hline & SD & 0.35 & 0.34 & 0.42 & 0.41 & & \\
\hline \multirow{2}{*}{ Organic food } & Mean & 3.09 & 2.97 & 2.87 & 3.13 & \multirow{2}{*}{4.469} & \multirow{2}{*}{$0.004 * *$} \\
\hline & SD & 0.52 & 0.46 & 0.53 & 0.64 & & \\
\hline \multirow{2}{*}{ Willingness to pay } & Mean & 2.93 & 2.93 & 2.93 & 2.99 & \multirow{2}{*}{0.380} & \multirow{2}{*}{0.768} \\
\hline & SD & 0.45 & 0.50 & 0.49 & 0.51 & & \\
\hline \multirow{2}{*}{ Consumer confidence } & Mean & 2.67 & 2.54 & 2.63 & 2.83 & \multirow{2}{*}{3.211} & \multirow{2}{*}{$0.023 *$} \\
\hline & SD & 0.50 & 0.51 & 0.68 & 0.56 & & \\
\hline \multirow{2}{*}{ PRACTICE } & Mean & 3.58 & 3.68 & 3.58 & 3.75 & \multirow{2}{*}{2.454} & \multirow{2}{*}{0.063} \\
\hline & SD & 0.48 & $\mathbf{0 . 5 3}$ & 0.47 & 0.51 & & \\
\hline \multirow{2}{*}{ Dining-unit selections } & Mean & 3.75 & 3.91 & 3.75 & 3.85 & \multirow{2}{*}{2.178} & \multirow{2}{*}{0.090} \\
\hline & SD & 0.49 & 0.53 & 0.47 & 0.51 & & \\
\hline & Mean & 3.36 & 3.37 & 3.37 & 3.61 & & \\
\hline Label information & SD & 0.67 & 0.77 & 0.63 & 0.74 & 2.657 & $0.048^{*}$ \\
\hline
\end{tabular}


A case study on the food safety issues of college students in Taiwan

Table 12

Multiple comparisons of ANOVA for Year-grade group

\begin{tabular}{|c|c|c|c|c|}
\hline \multicolumn{5}{|l|}{ Tukey HSD } \\
\hline Dependent Variable & & & Mean Difference (I-J) & Sig. \\
\hline \multirow{9}{*}{ Information sources } & \multirow{3}{*}{ Freshman } & Sophomore & -0.00762 & 1.000 \\
\hline & & Junior & $0.19515^{*}$ & 0.045 \\
\hline & & Senior & -0.06938 & 0.810 \\
\hline & \multirow{3}{*}{ Sophomore } & Freshman & 0.00762 & 1.000 \\
\hline & & Junior & 0.20278 & 0.124 \\
\hline & & Senior & -0.06175 & 0.915 \\
\hline & \multirow{3}{*}{ Junior } & Freshman & $-0.19515^{*}$ & 0.045 \\
\hline & & Sophomore & -0.20278 & 0.124 \\
\hline & & Senior & $-0.26453 *$ & 0.011 \\
\hline \multirow{9}{*}{ ATTITUDE } & \multirow[t]{3}{*}{ Freshman } & Sophomore & 0.09176 & 0.398 \\
\hline & & Junior & 0.08364 & 0.361 \\
\hline & & Senior & -0.09019 & 0.333 \\
\hline & \multirow[t]{3}{*}{ Sophomore } & Freshman & -0.09176 & 0.398 \\
\hline & & Junior & -0.00812 & 0.999 \\
\hline & & Senior & $-0.18195^{*}$ & 0.028 \\
\hline & \multirow[t]{3}{*}{ Junior } & Freshman & -0.08364 & 0.361 \\
\hline & & Sophomore & 0.00812 & 0.999 \\
\hline & & Senior & $-0.17383^{*}$ & 0.017 \\
\hline \multirow{9}{*}{ Organic food } & \multirow{3}{*}{ Freshman } & Sophomore & 0.12619 & 0.433 \\
\hline & & Junior & $0.22619 *$ & 0.012 \\
\hline & & Senior & -0.03535 & 0.967 \\
\hline & \multirow{3}{*}{ Sophomore } & Freshman & -0.12619 & 0.433 \\
\hline & & Junior & 0.10000 & 0.685 \\
\hline & & Senior & -0.16154 & 0.306 \\
\hline & \multirow{3}{*}{ Junior } & Freshman & $-0.22619^{*}$ & 0.012 \\
\hline & & Sophomore & -0.10000 & 0.685 \\
\hline & & Senior & $-0.26154 *$ & 0.010 \\
\hline \multirow{9}{*}{ Consumer confidence } & \multirow{3}{*}{ Freshman } & Sophomore & 0.13426 & 0.414 \\
\hline & & Junior & 0.03759 & 0.961 \\
\hline & & Senior & -0.15472 & 0.213 \\
\hline & \multirow{3}{*}{ Sophomore } & Freshman & -0.13426 & 0.414 \\
\hline & & Junior & -0.09667 & 0.734 \\
\hline & & Senior & $-0.28897 *$ & 0.016 \\
\hline & \multirow{3}{*}{ Junior } & Freshman & -0.03759 & 0.961 \\
\hline & & Sophomore & 0.09667 & 0.734 \\
\hline & & Senior & -0.19231 & 0.125 \\
\hline \multirow{9}{*}{ Label information } & \multirow{3}{*}{ Freshman } & Sophomore & -0.01871 & 0.998 \\
\hline & & Junior & -0.01247 & 0.999 \\
\hline & & Senior & $-0.25662 *$ & 0.045 \\
\hline & \multirow{3}{*}{ Sophomore } & Freshman & 0.01871 & 0.998 \\
\hline & & Junior & 0.00623 & 1.000 \\
\hline & & Senior & -0.23791 & 0.190 \\
\hline & \multirow{3}{*}{ Junior } & Freshman & 0.01247 & 0.999 \\
\hline & & Sophomore & -0.00623 & 1.000 \\
\hline & & Senior & -0.24415 & 0.106 \\
\hline
\end{tabular}

Note. ${ }^{*}$. The mean difference is significant at the 0.05 level.

\subsection{Correlations}

As shown in table 13 the relationship among Knowledge, Attitude and Practice are discovered using Pearson correlation coefficient. It is found that three dimensions have significant correlations with others as suggested by Sig 2-tailed ( $\mathrm{p}$ value is less than 0.01). Whereby, Knowledge and Practice have the significant relationship by Pearson coefficient value of $0.485(n=365)$. Next is the significant relationship between Attitude and Practice ( $\mathrm{r}$ 
Dong, T. T. M., \& Ching, G. S.

$=0.282, n=366$ ). Lastly, Knowledge is significantly correlated with Attitude with Pearson coefficient of 0.204

$(\mathrm{n}=366)$.

\section{Table 13}

Correlation of KNOWLEDGE, ATTITUDE and PRACTICE dimension

\begin{tabular}{lccc}
\hline & KNOWLEDGE & ATTITUDE & PRACTICE \\
\hline KNOWLEDGE & 1 & & \\
ATTITUDE & $.204^{* *}$ & 1 & \\
PRACTICE & $.485^{* *}$ & $.282^{* *}$ & 1 \\
\hline Note. ${ }^{* *} \mathrm{p}<0.01$ & & &
\end{tabular}

\subsection{Structure Equation Modeling (SEM)}

Before conducting SEM model, correlation matrices means and standard deviation of eight factors are used to analyze factor loading and T-value of these factors. Most of the standardized factor loadings result adequate, however, the loadings of some factors are quite low (e.g. A.B =0.43, A.C or K.B = 0.45). Furthermore, T-value of organic food (A.A) and dining-unit selection (P.B) cannot be loaded.

\section{Table 14}

Factor loading and T-value of factors

\begin{tabular}{lccccc}
\hline & $n$ & Mean & SD & Factor L. & T-value \\
\hline KNOWLEDGE & & & & & \\
General knowledge (K.A) & 368 & 3.09 & 0.71 & 0.49 & 7.73 \\
Information sources (K.B) & 369 & 3.26 & 0.56 & 0.45 & 7.23 \\
Responsibility awareness (K.C) & 368 & 3.79 & 0.7 & 0.52 & 8.29 \\
ATTITUDE & & & & & \\
Organic food (A.A) & 368 & 3.02 & 0.55 & 0.66 & \\
Willingness to pay (A.B) & 368 & 2.94 & 0.48 & 0.43 & 4.70 \\
Consumer confidence (A.C) & 369 & 2.67 & 0.57 & 0.45 & 4.75 \\
PRACTICE & & & & & \\
Dining-unit selection (P.B) & 368 & 3.89 & 0.51 & 0.64 & 8.12 \\
Information label (P.C) & 367 & 3.42 & 0.7 & 0.70 & \\
\hline
\end{tabular}

Figure 2. The model of SEM
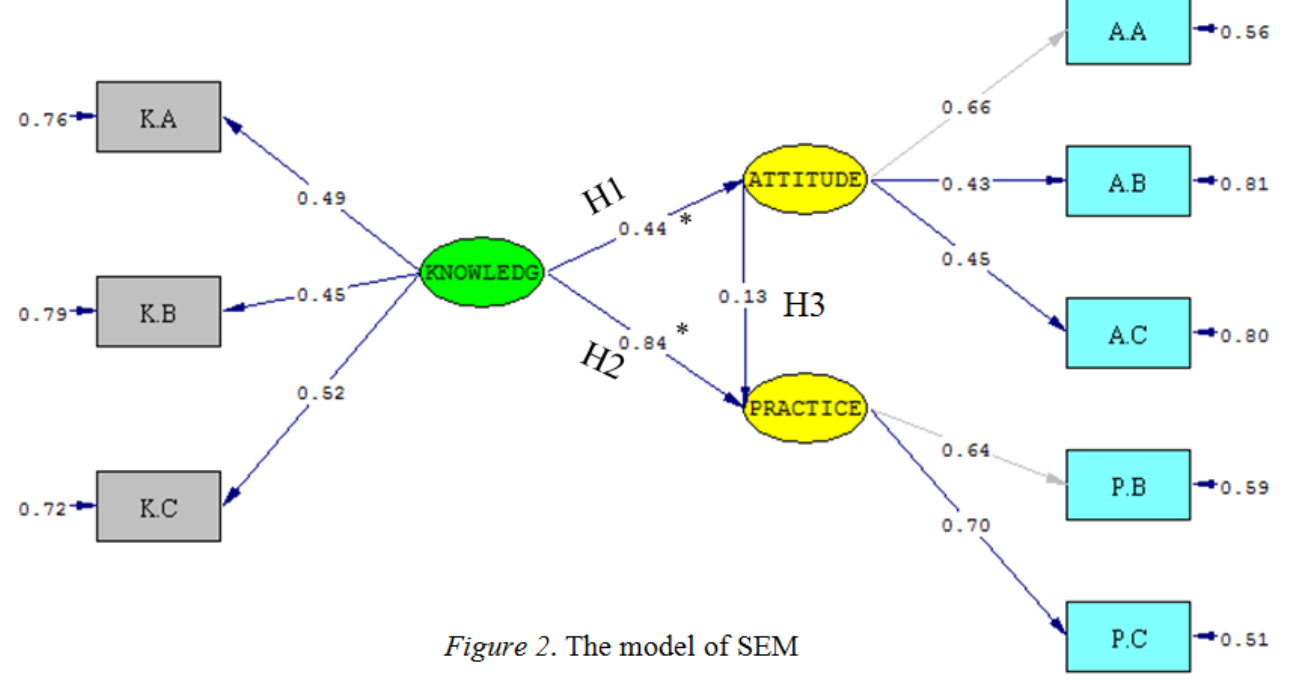

$$
\begin{array}{clc}
\text { Note. } * \mathrm{p}<0.01 & & \\
\chi^{2}=71.35 & \mathrm{~d} f=17 & \mathrm{p}=0.000 \\
\mathrm{CFI}=0.89 & \mathrm{GFI}=0.95 & \mathrm{IFI}=0.90 \\
& & \\
& \text { K.B }- \text { Information sources } \\
\text { K.A - general knowledge } & \text { A.B }- \text { willingness to pay } \\
\text { A.A - organic food } & \text { P.C - label information }
\end{array}
$$$$
\text { RMSEA }=0.093
$$$$
\mathrm{NFI}=0.87
$$ 
The model of consumers' knowledge, attitude and practice towards food safety issue is to verify by SEM (see figure). Chi-square $\left(\chi^{2}\right)$ for the measurement model is $71.35(p=0.000)$, with 17 degrees of freedom $(\mathrm{d} f)$. The ratio of $\chi^{2} / \mathrm{d} f$ for the measure model in this research is 4.2 , although it is not a good fit for the sample, but it still remains within an acceptable range ( $<5$ is acceptable). Additionally, all model's goodness-of-fit, according to CFI, GFI, IFI, NFI, remain marginal of 0.9. Analytical results indicate a good fit to data, as fit indicates exceeded or approached 0.9. Nonetheless, the value of RMSEA (RMSEA $=0.093>0.08$ ) is not satisfied.

The results obtained from SEM analysis outlines positive influence of Knowledge on Attitude (T-value is 4.27; $\mathrm{r}=0.204, p<0.01$ ) and Practice (T-value is $6.72 ; \mathrm{r}=0.485, p<0.01$ ). However, significant relationship between Attitude and Practice (T-value is 1.14) is not found. Therefore:

$>$ Hypothesis 1 "Knowledge has positive impact to attitude" is statistically supported.

Dypothesis 2 "Knowledge has positive impact to practice" is statistically supported.

$>$ Hypothesis 3 "Attitude has positive impact to practice" is not supported.

\section{Conclusion}

This research consists of 369 respondents who are college students of Lunghwa University (LHU). The results of current research indicate that the extents of students' knowledge, attitude and behavior have not been high, especially in knowledge and attitude. The correlation of those three dimensions points out the significant inter-relationships of knowledge, attitude and practice; however, the analyzing of structure equation modeling just proves that their knowledge has positive impact to their attitude (H1) and more significantly influence on their practice (H2), but attitude does not much affect behavior (H3 is not supported).

In overall, students do not know much about issues of food safety in general knowledge; extra educational activities conducted about those common issues should be more frequent to show how to protect them in the related issue. Furthermore, the study reveals that respondents do not feel considerably confident of their knowledge in food safety, the safety of food they consume, as well as their handling in food safety issue.

Besides, in the process of obtaining food safety information, students' judge on health professionals (like doctors, nurses, dietitians) or those they have closed-relationships (such as their family members or trusted friends) rather than the information from food manufacturers, the media or the government. As regard for being in charge of food safety, consumers are aware of there are biggest responsibilities of the government and food industry, and the followings are the media, academia and farmers. Nonetheless, the government and Taiwanese food supply are considered as two agencies which participants are much less confident about.

Additionally, in factors of organic food and willingness-to-pay, although students quite agree organic products are healthier and superior quality, they also admit that quality foods which organic food is an example have unreasonable price. However, though consumers do not really demonstrate their preference for quality food as "organic food", but declare that "constantly paying for sampling new foods".

Referring to the eating frequency of students at given dining-units including at home, canteens of schools, food vendors, restaurants and leisure facilities, results exposes two venues where students most frequently have eaten are at home and canteens of schools. Interestingly, both genders have the same regularity in eating at home, canteens of schools as well as leisure facilities, but an exception of at food vendors where male ate more regular than female. More importantly, the study founds although how much students expend on food consuming and how different they have the eating frequency at dining-units among groups of spending, their eating frequency at school-canteens is still the same.

As regards dining-unit selections, it is obvious that most three preferred criteria participants choose are the cleanliness and hygiene of dining-units, tasty dishes, and reasonable prices along convenience. Social connection 
is a further key variable in choosing where-to-eat (e.g. going with family members, going with friends). Alongside those variables, students still pay attention for the promotion of the food stores; but it is seen as the ultimate effect on their choices.

In line with label information factor, expiration date is the most familiar information on packages for students, accounting for the reason they always consider this information firstly with a highest proportion than other variables. The followings are brand names and cooking instruction/ preparation time. Ultimately, country of origin labeling, health benefits and the advertisement of natural or organic food in package are the groups of lowest information-concern of consumers in food products' labels.

The percentages of freshmen, sophomores, juniors, seniors in the study are 38.2, 16.3, 24.4, 21.1, respectively. Results found that seniors are much more significantly different from students of other year grades in trustworthy sources of food safety information, confidence in this issue. Particularly, their attitude is more positive than other groups and this is most apparent in attitudes towards organic food. Similarly, freshmen are also progressive in organic food attitudes. However, although last year students would be normally expected that their knowledge and practice are better than students of other years, the results cannot find any significant differences in both sections among seniors and others.

In the monthly expenditure for food, nearly three-quarters of students (73\%) expend less than 4000NT and over a remaining quarter spend $4001-5000 \mathrm{NT}(10.9 \%)$ or more than 5000NT $(16.1 \%)$ each month. The study proves that the amount of $5000 \mathrm{NT}$ is the standard that consumer are willing to pay more in order to perceive quality-products. Moreover, it also exposes students paying more than 5000NT per month for their food consume have the eating frequency at food vendors, leisure facilities and particularly restaurants, higher than students paying less than this amount.

There are $70.5 \%$ of female and $29.5 \%$ of male students in current study. The study points out the differences between two gender groups regarding this figure. Whereby, female students are observed to be more convinced by information sources of food safety as well as more positive in their behaviors that they are more careful in choosing dining-units than males.

Concerning foodborne illness experience, 99 out of 369 participants (26.8\%) have this illness before. Therein, majority of respondents assume that they got this disease from street food vendors at $17.6 \%$, canteens of school at $14.9 \%$ and restaurants at $13.8 \%$ in overall. Surprisingly, there is not any significant difference found in knowledge, attitude and practice section as well as in eight factors belong to three dimensions between two groups of those who use to have experiences in foodborne illness before and those who never have it. Some reasons are given as: (1) this study has a small scale with 369 respondents, hence, the discrepancies are more likely to find in a larger scope; (2) it could be the problem of wording usage in current study that further researches could clarify; (3) students maybe not have enough interest in the issue of food safety, this should be the responsibilities of government, academia and media to educate students in this issue.

\subsection{Practical contribution}

Food safety is the shared responsibility of multiple actors that each plays their part (Jonge et al., 2008). This paper points out some suggestions for the academia, food industry and government, as recommendations to enhance the knowledge and attitude of students, through:

The need to educate about food safety - For customers, although the public concern is increasingly gearing toward food related diseases, but the high rate of food poisoning remains a major worry, proving that consumers' fundamental understanding about food safety is not sufficient to lead their practical behaviors to better the situation. Consequently, Knowledge can enhance motivation and adherence of safety guidelines. It is necessary to organize educational sessions for students. Students should be educated in order to expand their knowledge in many different sectors of food safety issues, such as: (1) the long-term effects on health because of 
A case study on the food safety issues of college students in Taiwan

the banned chemical and additives in food; (2) the brief introduction of new technologies are applied in food production; (3) the usage of label information on food products' packages; (4) the principles of raw materials selection, food processing and storage, or as five keys to safer food given by WHO for prevention of foodborne disease (keep clean, separate raw and cooked, cook thoroughly, keep food at safe temperature, use safe water and raw materials); (5) the knowledge of first aid in case of food poisoning is equally important related food-borne illness problems. Through the educational seasons, students may have better knowledge in this matter to protect themselves and avoid food poisoning in proper ways.

There are responsibilities of the health community, food industry, lawmakers and the media (Bruhn, 1999). Additionally, the academia (e.g., university, institution) need to share this responsibility, because the education from academia function as the priority and the most reliable and convenient source for students. There are multiple ways to organize educational sessions as some recommendations as follows:

$>\quad$ The academia should open up the extracurricular activities and invite the health professionals to share information of food safety to students.

$>\quad$ The academia should organize the "Food safety knowledge" contest to motivate students to keep themselves updated with latest knowledge about food safety

$>$ Government can corporate with the academia and related agencies in local areas organize the food safety related education activities for students' family members because students also learn food safety knowledge and get information from their family members. Besides, having a good knowledge will help customers, especially housewives, to be more prudential and more cautious in choosing what to purchase and consume for their families.

$>\quad$ Ministry of Health can corporate with the academia, the media to compose health education programs that consumer can have reliable sources to refer and improve their awareness of food safety.

In addition, students also need to have their responsibility involved in this matter. It is pointless when their behaviors belie their knowledge since what they understand about food safety is relevant.

\section{References}

Banati, D. (2011). Consumer response to food scandals and scares. Trends in Food Science \& Technology, 22, 56-60. http://dx.doi.org/10.1016/j.tifs.2010.12.007

Bruhn, C. M., \& Schutz, H. G. (1999), Consumer food safety knowledge and practices. Journal of Food Safety, 19, 73-87. http://dx.doi.org/10.1111/j.1745-4565.1999.tb00235.x

Chen, M. F. (2007). Consumer attitudes and purchase intentions in relation to organic foods in Taiwan: Moderating effects of food-related personality traits. Food Quality and Preference, 18, 1008-1021. http://dx.doi.org/10.1016/j.foodqual.2007.04.004

Cheng, W. C., Kuo, C. W., Chi, T. Y., Lin, L. C., Lee, C. H., Feng, R. L., \& Tsai, S. T. (2013). Investigation on the trend of food-borne disease outbreaks in Taiwan (1991-2010). Journal of Food and Drug Analysis, 21(3), 261-267. http://dx.doi.org/10.1016/j.jfda.2013.07.003

Jevsnik, M., Hlebec, V., \& Raspor., P. (2007). Consumers' awareness of food safety from shopping to eating. Food Control, 19, 737-745. http://dx.doi.org/10.1016/j.foodcont.2007.07.017

Jonge, J. D., Trijp, J. C., Lans, I. A., Renes, R. J., \& Frewer, L. J. (2008). How trust in institutions and organizations builds general consumer confidence in the safety of food: A decomposition of effects. Appetite, 51, 311-317. http://dx.doi.org/10.1016/j.appet.2008.03.008

Rozin, P., Fischler, C., Imada, S., Sarubin, A., \& Wrzesniewski, A. (1999). Attitude to food and the role of food in life in the USA, Japan, Flemish Belgium and France: Possible implications for the diet-health debate. Appetite, 33, 163-180. http://dx.doi.org/10.1006/appe.1999.0244

Sybille, G. (2011). Data collection, quantitative methods: The KAP survey model. Retrieved from 
Dong, T. T. M., \& Ching, G. S.

http://www.medecinsdumonde.org

Unusan, N. (2007). Consumer food safety knowledge and practices in the home in Turkey. Food Control, 18(1), 45-51. http://dx.doi.org/10.1016/j.foodcont.2005.08.006

World Health Organization (WHO). (2004). Food safety at risk in Asia and the Pacific. Retrieved from http://www.who.int/mediacentre/news/releases/2004/pr34/en/

Yen, T. H., Lin-Tan, D. T., \& Lin, J. L. (2011). Food safety involving ingestion of foods and beverages prepared with phthalate-plasticizer-containing clouding agents. Journal of the Formossan Medical Association, 110(11), 671-84. http://dx.doi.org/10.1016/j.jfma.2011.09.002 